\title{
The Effect of Hypertension on Adult Hippocampal Neurogenesis in Young Adult Spontaneously Hypertensive Rats and Dahl Rats
}

\author{
A. PISTIKOVA ${ }^{1,2^{*}}$, H. BROZKA ${ }^{1 *}$, M. BENCZE ${ }^{4}$, D. RADOSTOVA ${ }^{1,2}$, K. VALES $^{1,3}$, \\ A. STUCHLIK ${ }^{1 *}$ \\ * These authors contributed equally to this work.
}

${ }^{1}$ Department of Neurophysiology of Memory, Institute of Physiology of the Czech Academy of Sciences, Prague, Czech Republic, ${ }^{2}$ Second Faculty of Medicine, Charles University in Prague, Prague, Czech Republic, ${ }^{3}$ Department of Experimental Neurobiology, National Institute of Mental Health, Klecany, Czech Republic, ${ }^{4}$ Department of Experimental Hypertension, Institute of Physiology of the Czech Academy of Sciences, Prague, Czech Republic

Received December 2, 2016

Accepted March 8, 2017

On-line July 18, 2017

\begin{abstract}
Summary
The dentate gyrus of the hippocampus is one of the few places in the brain where neurogenesis occurs in adulthood. Nowadays, an increasing number of children and young adults are affected by hypertension, one of the factors in the development of cerebrovascular diseases and age-related cognitive deficits. Since these cognitive deficits are often hippocampus-dependent, it is possible that hypertension exerts this effect via decreasing adult neurogenesis which has been shown to be essential for a range of cognitive tasks. We used spontaneously hypertensive rats, which develop hypertension in the first weeks of life. Half of them were treated with the antihypertensive drug captopril. We found that the drug-induced lowering of blood pressure in this period did not affect the rate of adult neurogenesis. In a second experiment, we used another animal model of hypertension - salt-sensitive and salt-resistant strains of Dahl rats. A high-salt diet induces hypertension in the salt-sensitive strain, but not in the salt-resistant strain. The high-salt diet led to salt-induced hypertension, but did not affect the level of adult neurogenesis in the dentate gyrus of the hippocampus. We conclude that hypertension does not significantly affect the rate of hippocampal neurogenesis in young adult rats.
\end{abstract}

\section{Key words}

Adult neurogenesis • Captopril • Hypertension • Dahl rats • SHR

- Young animals

\section{Corresponding authors}

A. Pistikova and A. Stuchlik, Department of Neurophysiology of Memory, Institute of Physiology of the Czech Academy of Sciences, Vídeňská 1083, 14220 Prague, Czech Republic. E-mail: adela.pistikova@fgu.cas.cz or ales.stuchlik@fgu.cas.cz

\section{Introduction}

Hypertension is a chronic cardiovascular disease that is reaching epidemic proportions in western countries. Although hypertension is traditionally considered an ailment of old age, its prevalence is also increasing among children and youth (Falkner 2010). Nowadays it is well established that the hippocampus is specifically sensitive to the alterations in blood pressure (Sabbatini et al. 2002, Sabbatini et al. 2000). Importantly, hypertension can lead to the impairments in hippocampus-dependent processes such as learning and spatial orientation, even in the absence of clinical evidence of vascular damage (Harrington et al. 2000, Papademetriou 2005). Studies show that hypertension decreases (Pietranera et al. 2006, Pietranera et al. 2008, Pietranera et al. 2010, Shih et al. 2016) but also increases (Hwang et al. 2008, Kronenberg et al. 2007, Perfilieva et al. 2001) adult neurogenesis. Thus question remains, however, if hippocampal sensitivity to blood pressure also includes alterations of adult neurogenesis in the dentate gyrus (DG). 
Neuroscientists recognize a plethora of intrinsic and extrinsic factors that affect the rate of adult neurogenesis in the DG of the hippocampus. Incidentally, the same factors that decrease adult neurogenesis in the DG (chronic stress, aging and depression to list a few) are also associated with impaired cognitive performance (Lee et al. 2012, Song et al. 2006). Awareness of the factors affecting neurogenesis is therefore of utmost importance. Moreover, special attention should be paid to factors acting in youth, because this is the period when neurogenesis is greatest (Seki and Arai 1995). High levels of neurogenesis in children and young adults could serve some important role in cognition since it co-occurs with the age where most learning takes place (Amrein and Lipp 2009).

In the present study we tested the hypothesis that early hypertension is associated with a decrease of adult neurogenesis in the DG. Compared to most other studies we used younger animals in order to capture the time of greatest neurogenesis, and a time where neurogenesis may be most important to cognition (Amrein and Lipp 2009). We used two complementary approaches: 1) A drug-induced lowering of blood pressure in inbred spontaneously hypertensive rats (SHRs) treated with the antihypertensive drug captopril; and 2) An increase in blood pressure in a salt-sensitive strain of inbred Dahl (Dahl SS) rats on a diet with high salt content. Inbred salt-resistant Dahl (Dahl SR) rats were used as controls for the effect of salt intake on adult DG neurogenesis without a concomitant increase in blood pressure. SHR inbred rats are a commonly used model of essential hypertension, which develops during the first 3 months of life. Micro-anatomical changes such as increased ventricle size, increased astrogliosis and decreased hippocampal volume have been observed (Sabbatini et al. 2002, Sabbatini et al. 2000). Captopril, an angiotensinconverting enzyme (ACE) inhibitor, successfully reduces the increase of blood pressure with no observed serious side-effects (Richer et al. 1984). The model used here for induced hypertension is an inbred Dahl SS rats. Hypertension develops in the Dahl SS rats after increase of salt intake. In contrast, the Dahl SR rats do not develop high blood pressure even when high-salt diet is administered (Rapp and Dene 1985). Thus, these two strains are an ideal tool to explore the effects of saltinduced hypertension on adult neurogenesis (Dahl SS), as well as effects of high salt intake on adult neurogenesis without associated hypertension (Dahl SR). In both cases effects are thus examined between animals of the same genetic background. Moreover, we compared adult neurogenesis between these two strains. We labeled proliferating cells at one time point - two weeks prior to euthanasia, because two week old and older neurons are functionally important in learning and memory (Schmidt-Hieber et al. 2004). Our results indicate that neither the captopril treatment, hypertension induced by a high-salt diet, nor the high salt intake alone had an effect on adult neurogenesis.

\section{Methods}

\section{Animals}

Inbred animals (both SHRs and Dahl rats) from the breeding colony of the Institute of Physiology CAS arrived after weanling at the age of 28 days. Rats were housed in pairs or triplets in transparent plastic cages under standard light conditions in an air-conditioned animal room with a 12/12 light dark cycle with lights on at $6 \mathrm{am}$, constant temperature and humidity $\left(22 \pm 1^{\circ} \mathrm{C}\right.$; $50 \%$ ) and with food and water ad libitum. Rats were labeled with stripes on their tails for identification. All animal procedures were approved by the Local Animal Care Committee and complied with the Animal Protection Act of the Czech Republic, EU directive 2010/63/EC and NIH guidelines. The experiments used in this study were approved by the Committee for Proper Procedures in Animals and Welfare of the Institute of Physiology, Czech Academy of Sciences and by the Resort Committee of the Czech Academy of Sciences (Project of Experiments No. 136/2013).

In the first experiment we used 41 male SHRs. Rats were randomized into control $(\mathrm{n}=20)$ and captopriltreated groups $(n=21)$. Rats in the treatment group received captopril dissolved in the drinking water at $500 \mathrm{mg} / \mathrm{l}$, while control animals received - tap water. The captopril solution or tap water was administered for six weeks.

In the second experiment we used Dahl SS $(n=20)$ and Dahl SR $(n=20)$ male rats. Half of the Dahl SS and half of the Dahl SR groups were fed a special high-salt diet $(4 \% \mathrm{NaCl}$, Altromin $\mathrm{C}$ 1036). The remaining animals were fed a special low-salt diet $(0.04 \% \mathrm{NaCl}$, Altromin 1324). These diets were administered for six weeks.

\section{Bromodeoxyuridine labeling}

To detect the proliferation and survival of newborn neuronal cells we administered 
bromodeoxyuridine (BrdU) to all SHRs and Dahl rats by intraperitoneal injection at a dose of $50 \mathrm{mg} / \mathrm{kg}$ dissolved in saline $(20 \mathrm{mg} / \mathrm{ml})$ two weeks before euthanasia (Garthe et al. 2009). Figure 1 shows representative micrographs of BrdU+ cells in DG of hippocampus.

\section{Blood pressure measurement}

After six weeks of captopril medication or consumption of the salt diet we measured mean arterial blood pressure (MAP) in both SHRs and Dahl rats. MAP was measured under thiopental anesthesia $(50 \mathrm{mg} / \mathrm{kg})$ in the femoral artery using a catheter connected to a measuring device consisting of an MLT0380/D pressure transducer wired to a QUAD Bridge and PowerLab/8SP (AD Instruments Ltd., Australia). Visualization of experiment time line is in the Figure 2.

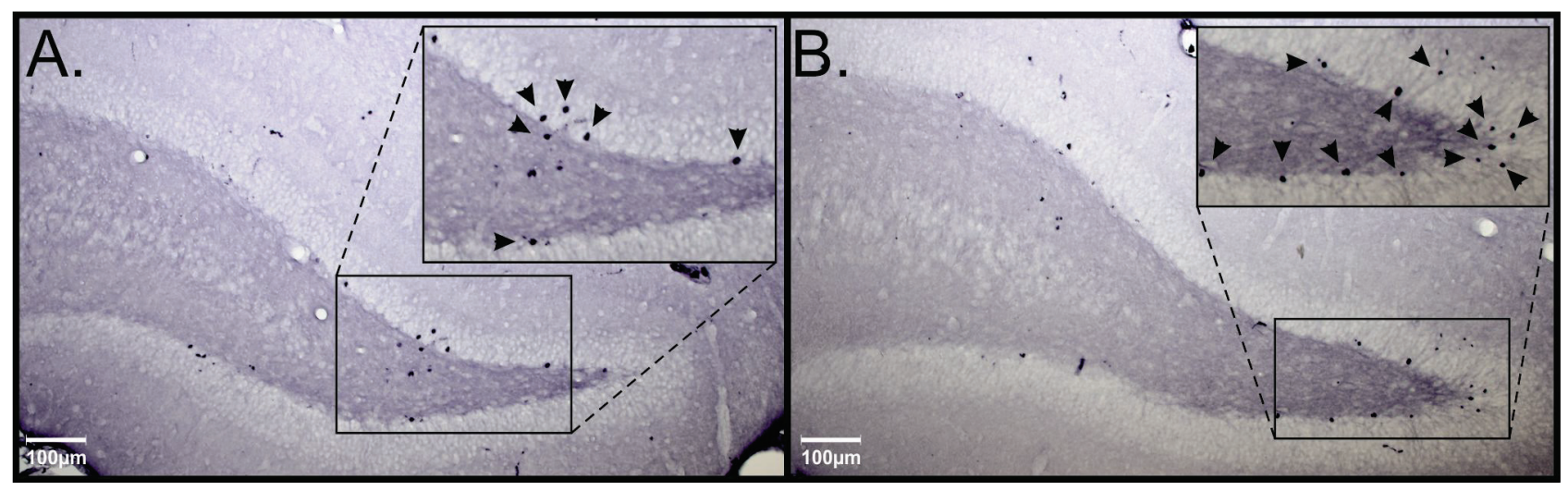

Fig. 1. Micrographs illustrating BrdU+ cells in DG of hippocampus in SHRs. (A) SHR with captopril treatment. (B) SHR control group. BrdU+ cells are shown by black arrows.

\section{SHRs control or captopril treatment}

\section{Dahl SS} consumption high salt or low salt diet

Dahl SR consumption high salt or low salt diet

weeks 0
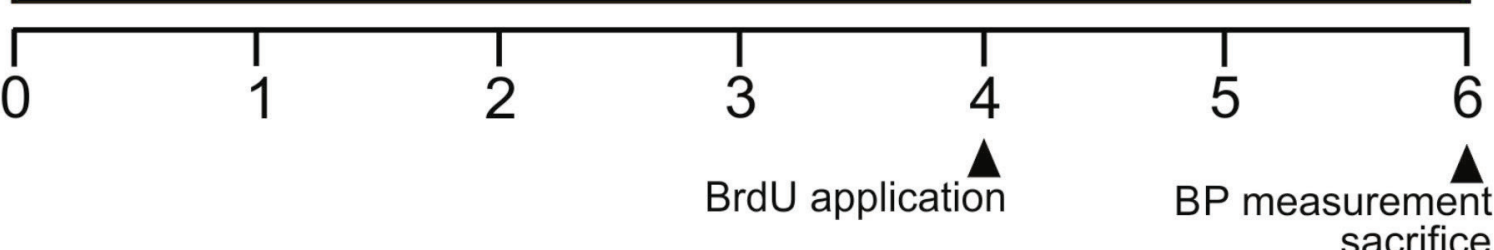

Fig. 2. Experimental scheme: In the first experiment SHRs received a captopril solution or tap water for six weeks. In the second experiment half of the Dahl SS and half of the Dahl SR groups were fed a high-salt diet and the remaining rats were fed a low-salt diet. Rats received these special diets for six weeks. In both experiments we administered BrdU by i.p. injection to all SHR and Dahl rats two weeks before sacrifice. After six weeks of captopril treatment or feeding special salt diets we measured arterial blood pressure (MAP) and perfused all rats transcardially for preparation of brain sections.

\section{Tissue preparation}

Immediately after blood pressure measurements animals were transcardially perfused by $0.1 \mathrm{M}$ phosphatebuffered solution (PBS) and subsequently by $4 \%$ formaldehyde. Following perfusions the brains were retrieved and kept in $4 \%$ formaldehyde for $24 \mathrm{~h}$ and cryoprotected in sucrose solutions (consecutively in 10, 20 and $30 \%$ ). Afterwards, brains were sectioned to $40 \mu \mathrm{m}$ coronal sections on a cryostat (Leica 1850) and stored in cryoprotectant solution (CPS) at $-20{ }^{\circ} \mathrm{C}$.

\section{BrdU Immunochemistry}

First, sections were transferred from CPS to Tris-buffered saline (TBS) and repeatedly rinsed. Sections were then placed into a solution of $\mathrm{H}_{2} \mathrm{O}_{2}$ and methanol in TBS to block endogenous peroxidase. Then, sections were washed in $\mathrm{NaCl} 0.9 \%$ to decrease the buffering of tissue. To denature DNA, sections were incubated in $2.5 \mathrm{~N} \mathrm{HCl}$ for $30 \mathrm{~min}$ at $38^{\circ} \mathrm{C}$. Next, sections were washed in PBS to eliminate background staining and quenched in blocking buffer (10\% donkey 
serum and $0.3 \%$ Triton $\mathrm{X}-100$ in PBS) for $1 \mathrm{~h}$. Immediately after, sections were incubated with a rat monoclonal anti-BrdU antibody (1:500; clone BU1/75, Serotec OBT0030) diluted in blocking buffer for $48 \mathrm{~h}$ at $4{ }^{\circ} \mathrm{C}$ in a cold room. The next day, sections were repeatedly rinsed in PBS. After washing, sections wer e incubated with a biotinylated donkey anti-rat secondary antibody (1:500, Jackson/Dianova, 712-065-153) diluted in PBS with $3 \%$ donkey serum and $0.3 \%$ Triton X-100 for $2.5 \mathrm{~h}$. Sections were then rinsed in PBS and incubated with avidin/biotin complexes conjugated with horseradish peroxidase. $9 \mu \mathrm{m} / \mathrm{ml}$ of each reagent (ABC elite kit standard, PK6100, Vector Laboratories, USA) was used diluted in PBS for $1 \mathrm{~h}$. Next, sections were placed in diaminobenzidine (DAB) solution $0.25 \mathrm{mg} / \mathrm{ml}$ in $\mathrm{PBS}$ (DAB, Sigma Aldrich, D5905) with $0.01 \% \mathrm{H}_{2} \mathrm{O}_{2}$ and $0.04 \% \mathrm{NiCl}_{2}$ followed by rinsing with tap water and PBS. Finally, sections were mounted on gelatin coated slides and cover-slipped (Neo-Mount $\AA$, Merck). BrdU+ cells were counted under a light microscope using a 40x objective. The upper focal plane was disregarded to avoid over-counting cells at the cutting surfaces. The whole area of the DG in each section was used to estimate total cell count. Specifically, BrdU+ cells were counted in each section bilaterally and this value was multiplied by six (sampling interval) to acquire an estimate of labeled cells for the whole DG.

\section{Data analysis}

Data was analyzed using SPSS software (SPSS Statistics for Windows, Version 23.0. USA). First, the distribution was assessed by the Kolmogorov-Smirnoff test. If data were not normally distributed we used a suitable transformation to achieve normally distributed data. Then, data were analyzed using an appropriate parametric test (analysis of variance (ANOVA) or t-test). Significance was accepted at a level of $\mathrm{p}<0.005$.

\section{Results}

Twelve control SHR animals and 13 captopriltreated animals were used in the analysis of MAP. Data was analyzed using an independent-sample t-test. We observed significantly lower MAP in the captopril-treated group compared to control group $([\mathrm{t}(23)=10.200$, $\mathrm{p}<0.001]$, Fig. 3A). When analyzing the number of BrdU+ cells, data point were removed in they were more than three standard deviations from the average. This was most likely due to incorrectly performed intraperitoneal injections containing BrdU which resulted in an absence of correctly labeled brain tissue. Therefore 19 control animals and 17 captopril-treated animals were used in the analysis. The independent-sample t-test did not show any effect of captopril treatment on the number of BrdU+ cells $([\mathrm{t}(34)=-1.298, \mathrm{p}=0.203]$, Fig. 3B).

Mean arterial blood pressure was recorded in 13 Dahl SS and 15 Dahl SR animals. Two-way analysis of variance was used to analyze the data - salt intake and rat strain were used as two independent variables. There was a significantly lower MAP in the Dahl SR compared to the Dahl SS rats $[F(1,24)=21.774, p<0.001]$. However, there was no overall significant change in MAP induced by the high salt diet $[F(1,24)=2.735, p=0.111]$. However, the interaction between genetic strain and salt diet was close to being significant $[F(1,24)=3.276, p=0.083]$. This suggests a strain-specific effect of salt on different Dahl rat strains, as has been reported in the literature (Rapp and Dene 1985). Moreover, we analyzed the difference in MAP between the high and low salt diet separately in the SS and SR strains. In the SS strain, the independent t-test showed a significant increase in MAP for the group on a high salt diet compared to the low salt $\operatorname{diet}[\mathrm{t}(11)=2.435, \mathrm{p}=0.033]$. In the SR strain there was no significant difference in MAP between the high salt and low salt diets $([\mathrm{t}(13)=-0.114, \mathrm{p}=0.911]$, Fig. $3 \mathrm{C})$. The analysis of BrdU+ cell numbers was conducted on $15 \mathrm{SS}$ and 13 SR animals. Data was analyzed using two-way ANOVA. There was no significant difference in the number of BrdU+ cells between the Dahl SR and SS strains $[F(1,23)=0.048, p=0.829]$. The effect of salt intake on the number of BrdU+ cells was also not significant $[F(1,23)=0.007, p=0.934]$ is shown in the Figure 3D. Moreover, there was no significant interaction between strains and type of salt diet $[F(1,23)=0.408$, $\mathrm{p}=0.529]$.

\section{Discussion}

In our experiments we found that hypertension in young adult rats did not affect the level of adult neurogenesis in the dentate gyrus (DG). In our first experiment we used SHRs that develop hypertension in the first months of their life. We found no differences in the number of BrdU+ cells in the DG of the hippocampus between untreated SHRs with hypertension and normotensive captopril-treated SHRs. In the second experiment we used two strains of Dahl rats, salt-sensitive (Dahl SS) and salt-resistant (Dahl SR). In Dahl SS rats 
there was no effect of hypertension on the number of BrdU+ cells. Similarly, in Dahl SR rats we also did not find any effect of high salt intake on adult neurogenesis. Moreover, there was no difference in BrdU+ cell numbers between the Dahl SS and Dahl SR rats.

There have been several other experiments that have studied cell proliferation /survival in the DG of the hippocampus in hypertensive animals compared to normotensive control animals, but our study is the first one to focus on young adult rats. Pietranera et al. (2006) used two animal models of hypertension: SHRs (compared to normotensive Wistar-Kyoto rat) and deoxycorticosterone-salt-induced hypertension rats (the DOCA-salt model; compared to control rats without DOCA-salt treatment). In both models they found a reduction of adult neurogenesis in the DG of the hippocampus measured by the number of BrdU+ cells. Further studies by this group confirmed these findings (Pietranera et al. 2008, Pietranera et al. 2010). Another study, using mice, was conducted by Shih et al. (2016). In their experiment hypertension was induced by the constriction of one of the two renal arteries (2K1C hypertension). In mice that developed hypertension they observed a reduction in cell proliferation measured by the number of BrdU+ cells and a reduction in the number of immature neurons measured by doublecortin positive cells $(\mathrm{DCX}+)$ in the DG. Compared to our study, there are several methodological differences that could have contributed to the different results. Primarily, these studies used older animals and most of them compared two different genetic strains. Nonetheless, several other studies have found the opposite result - an increased level of adult neurogenesis in hypertensive rats. Perfilieva et al. (2001) compared the number of BrdU+ cells between SHRs and Sprague Dawley (SD) rats. Both cell proliferation and cell survival was increased in SHRs measured by the number of BrdU+ cells after one day or 30 days after BrdU application. Kronenberg and colleagues (2007) showed an increase in the number of $\mathrm{DCX}+$ and BrdU+ cells in the DG both in SHR hypertensive strain and SHR strokeprone hypertensive strain compared to their genetic control Wistar Kyoto rats. Hwang et al. (2008) measured proliferation using the number of $\mathrm{DCX}+$ cells at various ages (1, 8 and 12 months) in SHRs compared to SD rats. At all ages the number of DCX+ cells in the DG was higher in SHRs. Since none of these latter experiments compared animals with the same genetic background, conclusions about the relationship between hypertension and adult neurogenesis can hardly be made. These variations in adult neurogenesis may simply reflect strain differences, as differences in adult neurogenesis were found also between strains of mice (Kempermann et al. 1997, Kim et al. 2009) and rats (Perfilieva et al. 2001).

Although we did not find any alteration of adult neurogenesis after the treatment with ACE inhibitor captopril, some literature suggests that the reduction of angiotensin II levels or the blockade of angiotensin (AT) receptor 1 could alter adult neurogenesis by a bloodpressure-independent mechanism. It has been speculated that this effect is mediated by reduced activation of the $\mathrm{AT}_{1}$ receptor, which is present on neurons, because inhibition of this receptor protects adult neurogenesis against stress (Ping et al. 2014). Moreover, ramipril, another ACE inhibitor, mitigated the radiation-induced reduction of adult neurogenesis (Jenrow et al. 2010). This observed effect was small but significant after 12 weeks of treatment. However, another study showed that ramipril treatment for 28 weeks did not alter neurogenesis (Lee et al. 2012). Similarly, L-158, an $\mathrm{AT}_{2}$ inhibitor, does not seem to influence neurogenesis in the rat brain (Conner et al. 2011). On the contrary, the systemic administration of angiotensin II, similar to the observed increases of angiotensin II level during exercise, also increases adult neurogenesis, whereas blockade of the $\mathrm{AT}_{1}$ receptor prevented this increase in adult neurogenesis (Mukuda et al. 2014). We did not observe any enhancing effect of captopril, which is in line with the results of studies that have utilized ACE inhibitors or blocked $\mathrm{AT}_{1}$ receptors. Our study thus indirectly supports the results that show that angiotensin II does not significantly affect adult neurogenesis in the dentate gyrus.

Our study has two major limitations. First, we did not assess neurogenesis by BrdU at different stages of maturation but we selected the time of maturation that appears critical in learning and memory (Schmidt-Hieber et al. 2004). Second, we did not characterize BrdU+ cells as being neurons. However, literature is consistent that more than $80 \%$ of newly generated cells are neurons (Cameron and McKay 2001, Leuner et al. 2010, Leuner et al. 2007, Sisti et al. 2007, Waddell and Shors 2008).

\section{Conflict of Interest}

There is no conflict of interest.

\section{Acknowledgements}

This work was supported by the Charles University in 
Prague, project GA UK 750214, GACR Center of Excellence P304/12/G069 and by Academic project M200111204. Institutional support for Institute of Physiology, CAS, was provided by RVO: 67985823. Institutional support for NIMH, CZ was provided by the project "Sustainability for the National Institute of Mental Health", under grant number LO1611, with financial support from the Ministry of Education, Youth and Sports of the Czech Republic under the NPUI program.

\section{Conclusions}

In both experiments, we found no effect of hypertension in young adult rats on adult neurogenesis in the DG of the hippocampus. Six weeks of a high-salt diet given to Dahl SS rats did not affect adult neurogenesis measured by BrdU incorporation into dividing cells.
Accordingly, no effect of high salt intake was seen in Dahl SR rats. Similarly, there was no effect on BrdU incorporation in the SHR model of genetic hypertension compared to SHR treated with the antihypertensive drug captopril.

\begin{abstract}
Abbreviations
ACE inhibitor - angiotensin-converting-enzyme inhibitor, AT - angiotensin, BrdU - bromodeoxyuridine, CPS - cryoprotectant solution, DAB - diaminobenzidine, Dahl SR - salt resistant strain of inbred Dahl rats, Dahl SS - salt sensitive strain of inbred Dahl rats, DCX - doublecortin, DG - dentate gyrus, IP - intraperitoneal, MAP - mean arterial blood pressure, PBS - phosphate-buffered saline, SD - Sprague Dawley, SHR - spontaneously hypertensive rats, TBS - Trisbuffered saline.
\end{abstract}

\section{References}

AMREIN I, LIPP HP: Adult hippocampal neurogenesis of mammals: evolution and life history. Biol Lett 5: 141-144, 2009.

CAMERON HA, MCKAY RD: Adult neurogenesis produces a large pool of new granule cells in the dentate gyrus. J Comp Neurol 435: 406-417, 2001.

CONNER KR, FORBES ME, LEE WH, LEE YW, RIDLLE DR: AT1 receptor antagonism does not influence early radiation-induced changes in microglial activation or neurogenesis in the normal rat brain. Radiat Res 176: 71-83, 2011.

FALKNER B: Hypertension in children and adolescents: epidemiology and natural history. Pediatr Nephrol 25: 1219-1224, 2010.

GARTHE A, BEHR J, KEMPERMANN G: Adult-generated hippocampal neurons allow the flexible use of spatially precise learning strategies. PLoS One 4: e5464, 2009.

HARRINGTON F, SAXBY BK, MCKEITH IG, WESNES K, FORD GA: Cognitive performance in hypertensive and normotensive older subjects. Hypertension 36: 1079-1082, 2000.

HWANG IK, YOON YS, CHOI JH, YOO KY, YI SS, CHUNG DW, KIM HJ, KIM CS, DO SG, SEONG JK, LEE IS, WON MH: Doublecortin-immunoreactive neuronal precursors in the dentate gyrus of spontaneously hypertensive rats at various age stages: comparison with Sprague-Dawley rats. J Vet Med Sci 70: 373-377, 2008.

JENROW KA, BROWN SL, LIU J, KOLOZSVARY A, LAPANOWSKI K, KIM JH: Ramipril mitigates radiationinduced impairment of neurogenesis in the rat dentate gyrus. Radiat Oncol 5: 6, 2010.

KEMPERMANN G, KUHN HG, GAGE FH: Genetic influence on neurogenesis in the dentate gyrus of adult mice. Proc Natl Acad Sci US A 94: 10409-10414, 1997.

KIM JS, JUNG J, LEE HJ, KIM JC, WANG H, KIM SH, SHIN T, MOON C: Differences in immunoreactivities of Ki-67 and doublecortin in the adult hippocampus in three strains of mice. Acta Histochem 111: 150-156, 2009.

KRONENBERG G, LIPPOLDT A, KEMPERMANN G: Two genetic rat models of arterial hypertension show different mechanisms by which adult hippocampal neurogenesis is increased. Dev Neurosci 29: 124-133, 2007.

LEE SW, GAGE FH, CLEMENSON GD: New neurons in an aged brain. Behav Brain Res 227: 497-507, 2012.

LEE TC, GREENE-SCHLOESSER D, PAYNE V, DIZ DI, HSU FC, KOOSHKI M, MUSTAFA R, RIDDLE DR, ZHAO W, CHAN MD, ROBBINS ME: Chronic administration of the angiotensin-converting enzyme inhibitor, ramipril, prevents fractionated whole-brain irradiation-induced perirhinal cortex-dependent cognitive impairment. Radiat Res 178: 46-56, 2012. 
LEUNER B, GLASPER ER, GOULD E: Sexual experience promotes adult neurogenesis in the hippocampus despite an initial elevation in stress hormones. PLoS One 5: e11597, 2010.

LEUNER B, MIRESCU C, NOIMAN L, GOULD E: Maternal experience inhibits the production of immature neurons in the hippocampus during the postpartum period through elevations in adrenal steroids. Hippocampus 17: 434-442, 2007.

MUKUDA T, KOYAMA Y, HAMASAKI S, KAIDOH T, FURUKAWA Y: Systemic angiotensin II and exerciseinduced neurogenesis in adult rat hippocampus. Brain Res 1588: 92-103, 2014.

PAPADEMETRIOU V: Hypertension and cognitive function. Blood pressure regulation and cognitive function: a review of the literature. Geriatrics 60: 20-22, 24, 2005.

PERFILIEVA E, RISEDAL A, NYBERG J, JOHANSSON BB, ERIKSSON PS: Gender and strain influence on neurogenesis in dentate gyrus of young rats. J Cereb Blood Flow Metab 21: 211-217, 2001.

PIETRANERA L, LIMA A, ROIG P, DE NICOLA AF: Involvement of brain-derived neurotrophic factor and neurogenesis in oestradiol neuroprotection of the hippocampus of hypertensive rats. $J$ Neuroendocrinol 22 : 1082-1092, 2010.

PIETRANERA L, SARAVIA F, GONZALEZ DENISELlE MC, ROIG P, LIMA A, DE NICOLA AF: Abnormalities of the hippocampus are similar in deoxycorticosterone acetate-salt hypertensive rats and spontaneously hypertensive rats. J Neuroendocrinol 18: 466-474, 2006.

PIETRANERA L, SARAVIA FE, ROIG P, LIMA A, DE NICOLA AF: Protective effects of estradiol in the brain of rats with genetic or mineralocorticoid-induced hypertension. Psychoneuroendocrinology 33: 270-281, 2008.

PING G, QIAN W, SONG G, ZHAOCHUN S: Valsartan reverses depressive/anxiety-like behavior and induces hippocampal neurogenesis and expression of BDNF protein in unpredictable chronic mild stress mice. Pharmacol Biochem Behav 124: 5-12, 2014.

RAPP JP, DENE H: Development and characteristics of inbred strains of Dahl salt- sensitive and salt-resistant rats. Hypertension 7: 340-349, 1985.

RICHER C, GIROUX B, PLOUIN PF, MAAREK B, GIUDICELLI JF: Captopril: pharmacokinetics, antihypertensive and biological effects in hypertensive patients. Br J Clin Pharmacol 17: 243-250, 1984.

SABBATINI M, CATALANI A, CONSOLIC C, MARLETTA N, TOMASSONI D, AVOLA R: The hippocampus in spontaneously hypertensive rats: an animal model of vascular dementia? Mech Ageing Dev 123: 547-559, 2002.

SABBATINI M, STROCCHI P, VITAIOLI L, AMENTA F: The hippocampus in spontaneously hypertensive rats: a quantitative microanatomical study. Neuroscience 100: 251-258, 2000.

SEKI T, ARAI Y: Age-related production of new granule cells in the adult dentate gyrus. Neuroreport 6: 2479-2482, 1995.

SHIH YH, TSAI SF, HUANG SH, CHIANG YT, HUGHES MW, WU SY, LEE CW, YANG TT, KUO YM: Hypertension impairs hippocampus-related adult neurogenesis, CA1 neuron dendritic arborization and long-term memory. Neuroscience 322: 346-357, 2016.

SCHMIDT-HIEBER C, JONAS P, BISCHOFBERGER J: Enhanced synaptic plasticity in newly generated granule cells of the adult hippocampus. Nature 429: 184-187, 2004.

SISTI HM, GLASS AL, SHORS TJ: Neurogenesis and the spacing effect: learning over time enhances memory and the survival of new neurons. Learn Mem 14: 368-375, 2007.

SONG L, CHE W, MIN-WEI W, MURUKAMI Y, MATSUMUTO K: Impairment of the spatial learning and memory induced by learned helplessness and chronic mild stress. Pharmacol Biochem Behav 83: 186-193, 2006.

WADDELL J, SHORS TJ: Neurogenesis, learning and associative strength. Eur J Neurosci 27: 3020-3028, 2008. 